\title{
Prevalence of Hepatitis B and C among Hemodialysis Patients of Tripura, India
}

\author{
Pradip Bhaumik, Kalyan Debnath
}

\begin{abstract}
Introduction: Hemodialysis is a trusted intermediate procedure for management of chronic kidney disease (CKD) patients. As such CKD is an immune-deficient state, hence, they may be infected by hepatitis B virus (HCV) and hepatitis $\mathrm{C}$ virus (HCV) during hemodialysis. Eventually, HBV and HCV infection is an important cause of morbidity and mortality among patients of hemodialysis. Prevalence of HBV and HCV infection among hemodialysis patients is highly variable.
\end{abstract}

Aim of the study: This study was designed to see the prevalence of HBV and HCV among hemodialysis patients of Tripura, India and to evaluate the mode of transmission.

Materials and methods: This is a single center prospective study among the patients who has come for hemodialysis at the Dialysis Unit of Agartala Government Medical College and Govinda Ballav Pant Hospital during the period of January 2011 to June 2011.

Results: Male predominance has been observed among the hemodialysis patients and mean age of the patients was 48.16 years. New HBV infection was found in $5.5 \%$ of the hemodialysis patients (cumulative $7.3 \%$ ) and $10.9 \%$ (cumulative $12.12 \%$ ) of patients got new HCV infection during hemodialysis. Coinfection with both HBV and HCV was found among $1.2 \%$ of hemodialysis patients. History of blood transfusion was found in $100 \%$ of newly infected HBV and HCV patients.

Discussion: The evaluation suggests that blood transfusion may be the single most important risk factor for HBV and HCV infection among hemodialysis patients. Newer methods of screening of blood in blood bank like nucleic acid test or polymerase chain reaction amplification of nucleic acids should be adopted to prevent HBV and HCV transmission

Abbreviations: HBV: Hepatitis B virus infection; HCV: Hepatitis C virus infection; CKD: Chronic kidney disease; PCR: Polymerase chain reaction; ID-NAT: Individual nucleic acid test.

Keywords: HBV, HCV, Hemodialysis, Tripura, India.

How to cite this article: Bhaumik P, Debnath K. Prevalence of Hepatitis B and C among Hemodialysis Patients of Tripura, India. Euroasian J Hepato-Gastroenterol 2012;2(1):10-13.

Source of support: Nil

Conflict of interest: None

\section{INTRODUCTION}

Hepatitis is a global health problem. It is estimated that there are approximately 400 million hepatitis B virus (HBV) carriers in the world, of whom over 500000 die annually from $\mathrm{HBV}$-associated liver disease. ${ }^{1}$ According to the third
National Health and Nutrition Examination Survey (NHANES), 3.9 million of the US civilian population have been infected with hepatitis $\mathrm{C}$ virus (HCV), of whom 2.7 million (74\%) have chronic infection. About $3 \%$ of the world population has been infected with $\mathrm{HCV}$ and 170 million people are chronic HCV carriers. $^{2}$

Hemodialysis is a trusted intermediate procedure for management of chronic kidney disease (CKD) patients. As such CKD is an immune deficient state, hence blood borne viral infection particularly $\mathrm{HBV}$ and $\mathrm{HCV}$ are important cause of morbidity and mortality of patients treated by hemodialysis. ${ }^{3-5}$ If CKD patients are infected with $\mathrm{HBV}$ and $\mathrm{HCV}$, it retards the posttransplant prognosis too. ${ }^{6}$ Patients on hemodialysis may be infected through blood transfusions, contamination of dialysis machines and equipments as well as interpersonal horizontal transmission in the dialysis units. ${ }^{7}$ Blood transfusion has been correlated with an increase in HBV infection. Hemodialysis patients with a long-term history were more likely to be infected than those with a short-term history. ${ }^{8}$ The risk for a patient to become HBV, positive increases 1.47 times due to 1 month of hemodialysis. ${ }^{9} \mathrm{HCV}$ seroprevalence ranged between 0.7 and $18.1 \%$ across different countries. ${ }^{10}$

Chandra et al from Center for Liver Research and Diagnostics, Hyderabad, India have reported that, among the patients of CKD and of either renal transplant or hemodialysis, 7\% had HBV infection alone, 46\% were infected with $\mathrm{HCV}$ alone, while $37.10 \%$ were found to have coinfection of both viruses. ${ }^{6} \mathrm{HCV}$ infection is common in patient on dialysis and currently is present in approximately $8 \%$ of patient in the United States. ${ }^{11,12}$ The annual risk of acute HCV infection is currently estimated by the center for disease control (CDC) to be $0.15 \%$ in hemodialysis patient. It is seen that the pooled prevalence of $\mathrm{HBV}$ infection among hemodialysis patients in China was $11.9 \%$ and $\mathrm{HCV}$ infection was $41.1 \% .{ }^{13} \mathrm{HBV} / \mathrm{HCV}$ coinfection was related to a longer time on hemodialysis, longer duration of infection and history of blood transfusion. ${ }^{14}$

Improved infection control and the availability of vaccines have reduced the incidence of $\mathrm{HBV}$ infection among hemodialysis patients from $3 \%$ in 1980 to $0.1 \%$ in 1993 in the United States and has remained stable in the past decades. ${ }^{15,16}$ However, dialysis patients have impaired antibody response to vaccines. 
The prevalence of $\mathrm{HCV}$ infection among hemodialysis patients is high and varies between countries (2-6\%) and between dialysis units within a single country. ${ }^{17}$ So, to reduce the burden of $\mathrm{HBV}$ and $\mathrm{HCV}$ infections among hemodialysis patients regular evaluation may play an important role. This study was planned to estimate the prevalence of $\mathrm{HBV}$ and $\mathrm{HCV}$ among hemodialysis patients of Tripura, India. The aim of the study was to assess (1) the prevalence of $\mathrm{HBV}$ and $\mathrm{HCV}$ among hemodialysis patients of Tripura, (2) evaluation of mode of transmission of HBV and $\mathrm{HCV}$ among hemodialysis patients, and (3) development of insights about prevention strategies.

\section{MATERIALS AND METHODS}

This is a prospective single center study. The study was conducted at Dialysis Unit of Agartala Government Medical College and GB Pant Hospital. This is the only dialysis unit of Tripura having 10 beds and providing hemodialysis to about 20 patients on an average everyday. As this is the only center, the study will reflect the status of $\mathrm{HBV}$ and HCV among hemodialysis patients of Tripura. The study was conducted for a period of 6 months from January 2011 to June 2011. All the patients visited dialysis unit in this period were included in this study. A patient was included for one time only. No patients were excluded from this study except who were not willing to participate.

A study protocol was designed and approved by the ethical committee of the institution. At the beginning of the study all the staffs of the hemodialysis unit were appraised about the study and similarly status of all the staffs in respect to $\mathrm{HBV}$ and $\mathrm{HCV}$ were evaluated to exclude any provider to patients transmission.

Initially every patient was explained about the protocol of the study and a written consent was taken. After that before hemodialysis $5 \mathrm{ml}$ of blood was collected. The blood sample was allowed to stand for sufficient time for separation of serum. The sample was then centrifuged and serum was separated and preserved at $-20^{\circ} \mathrm{C}$. The next day the serum sample was tested for HBV and HCV by ELISA Reader (Thermo Scientific Multiskan EX,Thermo Fisher Scientific Oy, Vantaa, Finland.) using reagent for HBsAg and AntiHCV (General Biological Corp, Taiwan). The positive samples were rechecked and negative samples were randomly reexamined for confirmation. The results were tabulated and analyzed.

\section{RESULTS}

All patients attending Dialysis Unit of Agartala Government Medical College and GB Pant Hospital during the period of January, 2011 to June, 2011 were studied, evaluated and analyzed. Total 165 patients attended the hemodialysis unit. Out of this 120 were males and 45 were females. Most of the patients were between 40 and 60 years of age and mean age was 48.16 years. All the patients were clinically evaluated and detail history of blood transfusion, duration of hemodialysis and all other variables were noted.

From the baseline study it was found that three (1.8\%) patients were HBsAg-positive and two $(1.2 \%)$ patients were Anti-HCV-positive at the beginning of the hemodialysis. They were on separate machine of hemodialysis to prevent cross infection.

Total 106 patients out of 165 patients were vaccinated against HBV before commencing hemodialysis, 47 patients were vaccinated during the time of hemodialysis and 12 patients were not yet vaccinated against $\mathrm{HBV}$ at the time of the study.

From HBsAg and Anti-HCV analysis of all patients it has been found that total nine $(5.5 \%)$ patients were newly positive for HBsAg and after inclusion of previously positive patients total positive for HBsAg were $7.3 \%$. Similarly, newly positive patients for anti-HCV were $18(10.9 \%)$ and including already positive individuals total $20(12.12 \%)$ patients were infected. Two previously HBsAg-positive patients became positive for anti-HCV during hemodialysis. Hence, we have two $(1.2 \%)$ patients of $\mathrm{HBV} / \mathrm{HCV}$ coinfection.

Another interesting finding is that total 105 (63.6\%) patients received blood transfusion before or during the time of hemodialysis. Out of nine newly HBsAg-positive patients all of them received blood transfusion before or during the time of hemodialysis (Table 1). Similarly, all anti-HCVpositive patients received blood transfusion. Patients those who have not received even a single unit of blood none of them became HBsAg or Anti-HCV positive (Table 1). However, patients those who were HBsAg or Anti-HCV negative, $56.8 \%$ of them are blood transfusion recipient.

Among the newly HBsAg-positive patients $66.7 \%$ were between the age of 30 and 40 years (mean age 37.5 years) and $83.33 \%$ newly anti-HCV-positive patients were between 21 and 40 years of age (mean age 45.25 years) and cumulative mean age of the both HBV-and HCV-positive hemodialysis patients were 44.09 years.

\begin{tabular}{lccc}
\multicolumn{4}{c}{ Table 1: Hepatitis B and C virus infections among hemodialysis patients } \\
\hline Patients & $H B s A g(\%)$ & Anti-HCV (\%) & $H B s A g+$ Anti-HCV (\%) \\
\hline Before hemodialysis & 1.8 & 1.2 & 0 \\
During hemodialysis & 5.5 & 10.9 & 1.2 \\
\hline Total & 7.3 & 12.1 & 1.2 \\
\hline
\end{tabular}


It is also found that the mean duration of hemodialysis of infected patients was 1 year and 1 month whereas for noninfected patients it was near about 8 months.

It was observed that all $\mathrm{HBV}$ and $\mathrm{HCV}$ infected patients had already undergone AV fistula operation but only 53.7\% noninfected patients had the history of fistula operation.

Out of total nine newly positive-HBV infected patients no one was vaccinated before the diagnosis of CKD. Five patients were vaccinated just before hemodialysis and four were not yet vaccinated.

\section{DISCUSSION}

It has been reported that hemodialysis increases the possibility of blood borne viral infection but the prevalence is variable from hemodialysis center to center, region to region and country to country and high-cost hemodialysis center $v s$ low-cost hemodialysis center. It is not well understood whether this variability has got any relationship with the basic prevalence of the disease in the community. In most of the study HBV infection among hemodialysis patients was between 4 and $11 \%$ and $\mathrm{HCV}$ infection was between 8 and 12\%. In India, reported study of HBV and $\mathrm{HCV}$ infection among hemodialysis patient is variable. Reddy et al have reported that among hemodialysis patients $5.9 \%$ were $\mathrm{HCV}$-positive while $1.4 \%$ patients had $\mathrm{HBV}$ infection and $3.7 \%$ had coinfection with $\mathrm{HBV}$ and HCV. ${ }^{18}$ Chandra et al have reported that among the patients of CKD, renal transplant or hemodialysis, HBV, HCV and coinfection of both viruses were 7, 46 and $37.10 \%$ respectively. ${ }^{6}$ In the community study of Tripura it is found that prevalence of HBV among general population is around $4 \%$ whereas $\mathrm{HCV}$ is less than $1 \%$ (unpublished data).

Dialysis center at Agartala Government Medical College and GB Pant Hospital is the only dialysis center in Tripura; hence it reflects the prevalence of HBV and HCV in hemodialysis patients of Tripura. In our study we have found that $5.5 \%$ of hemodialysis patients were newly infected with HBV. It shows that most of the hemodialysis patients were vaccinated just before hemodialysis or not yet vaccinated. Probably, it did not allow development of full fledged passive immunity. Further, immunogenicity of CKD patients is less than normal. The study also demonstrates that this may got a positive correlation.

On the other hand $10.9 \%$ of patients became newly positive for anti-HCV. This is comparative with other centers, but interesting finding is that $\mathrm{HCV}$ infection among hemodialysis patients are occurring at a much early age than general population. This may increase the threat of $\mathrm{HCV}$ transmission. It has been observed that all HCV-positive patients had the history of blood transfusion. Patients who had not received any blood transfusion, none of them was positive for anti-HCV. It shows that blood transfusion is a major source of HCV infection among hemodialysis patients. It is understood that all blood are screened before transfusion. Probably present method of blood screening could not detect some of HBV- and HCV-positive blood samples. Hence, screening of blood for HBV and HCV before transfusion should be done by PCR or by testing nucleic acids. ${ }^{19}$ Though these are expensive but yield is very high.

Duration of hemodialysis is also a risk factor for getting infection. As longer the duration there is more possibility of getting infection by HBV or HCV.

Our study reveals that there is increased transmission of $\mathrm{HBV}$ and HCV infections during hemodialysis of CKD patients and most possible cause could be blood transfusion. Other source of infection like surgery and cross infection may contribute to some extent but that may not be so significant. All patients of CKD should be vaccinated against hepatitis B by following standard vaccination norms (in adults $2 \mathrm{ml}$ at 0-1-2-6 months and if required booster every year).

Blood screening methods in blood bank needs further improvement and newer technique like PCR, ID-NAT, etc. should be adopted. ${ }^{20}$ Voluntary blood donation may reduce the burden of blood borne viral infection, however, in a community where $\mathrm{HBV}$ and $\mathrm{HCV}$ infection prevalence is higher needs adoption of further precautionary measures to reduce mortality and morbidity among CKD patients.

\section{REFERENCES}

1. Lavanchy D. Hepatitis B virus epidemiology, disease burden, treatment, and current and emerging prevention and control measures. J Viral Hepat 2004;11:97-107.

2. WHO global surveillance and control of hepatitis C. Report of a WHO consultation organized in collaboration with the viral hepatitis prevention board, Antwerp, Belgium. J Viral Hepat 1999;6:35-47.

3. Zacks SL, Fried MW. Hepatitis B and C and renal failure. Infect Dis Clin North Am 2001;15:877-99.

4. Steketee RW, Ziarnik ME, Davis JP, et al. Sero-response to hepatitis $B$ vaccine in patients and staff of renal dialysis centers, Wisconsis. Am J Epidemiol 1988;127:772-82.

5. Lofgren B, Nordenfelt E, Lindholm T, et al. A 10-year follow-up of a hepatitis B epidemic in a dialysis unit. Scand J Infect Dis 1982;14:165-69.

6. Chandra M, Khaja MN, Hussain MM, et al. Prevalence of hepatitis $\mathrm{B}$ and $\mathrm{C}$ viral infections in Indian patients with chronic renal failure. Intervirology 2004;47:374-76.

7. Schiff's diseases of the liver (10th ed), volume-I.

8. Wang C, Sun J, Zhu B, et al. Hepatitis B virus infection and related factors in hemodialysis patients in China-systemic review and meta-analysis. Ren Fail 2010;32;1255-64.

9. Carrilho FJ, Moraces CR, Pinho JR, et al. Hepatitis B virus infection in hemodialysis centers from Santa Catarina state, Southern Brazil. Predictive risk factors for infection and molecular epidemiology. BMC Public Health 2004;4:13. 
10. Johnson DW, Dent H, Yao Q, et al. Frequencies of hepatitis B and $\mathrm{C}$ infection among hemodialysis and peritoneal dialysis patients in Asia-Pacific countries: Analysis of registry data. Nephrol Dial Transplant 2009;24;1598-603.

11. Zeldis JB, Depner TA, Kuramoto IK, et al. The prevalence of hepatitis $\mathrm{C}$ virus antibodies among hemodialysis patients. Ann Intern Med 1990;112:958-60.

12. Tokars JI, Finelli L, Alter MJ, et al. National surveillance of dialysis associated diseases in the United States, 2011. Semin Dial 2004;17:310-19.

13. Sun J, Yu R, Zhu B, Wu J, Larsen S, Zhao W. Hepatitis C infection and related factors in hemodialysis patients in China: Systemic review and meta-analysis. Ren Fail 2009;31:610-20.

14. Moutinho RS, Perez RM, Pace FH, et al. Lack of impact of hepatitis $\mathrm{C}$ virus coinfection in end-stage renal diseases patients with hepatitis B virus infection. Transplant Proc 2005;37: 2080-82.

15. CDC. Outbreaks of hepatitis B virus infection among hemodialysis patients - California, Nebraska and Texas 1994. MMWR Morb Mortal Wkly Rep 1996;45:285-89.

16. Finelli L, Miller JT, Tokars JI, et al. National surveillance of dialysis associated diseases in the United States 2002. Semin Dial 2005;18:52-61.

17. Alavian SM, Bagheri-Lankarani K, Mahdavi-Mazdeh M, Nourozi S, et al. Hepatitis B and C in Dialysis Units in Iran: Changing the epidemiology. Hemodial Int 2008;12:378-82.
18. Reddy GA, Dakshinamurthy KV, Neelaprasad P, Ganghadhar T, Lakshmi V. Prevalence of HBV and HCV dual infection in patients on hemodialysis. Indian Journal of Medical Microbiology 2005, 10/23, Issue I: 41-43.

19. Kuhns MC, Busch MP, et al. New strategies for blood donor screening for hepatitis B virus: Nucleic acid testing versus immunoassay methods. Mol Diagn Ther 2006;10:77-91.

20. Vermeulen M, Lelie N, Sykes W, Crookes R, Swanevelder J, Gaggia L, et al. Impact of individual- donation nucleic acid testing on risk of human immunodeficiency virus, hepatitis B virus and hepatitis $\mathrm{C}$ virus transmission by blood transfusion in South Africa. Transfusion 2009;49:1115-25.

\section{ABOUT THE AUTHORS}

\section{Pradip Bhaumik (Corresponding Author)}

Associate Professor, Department of Medicine, Agartala Government Medical College, Road No. 1, Dhaleshwar, Agartala-799007, Tripura India, e-mail: pradipbhaumik1@yahoo.com

\section{Kalyan Debnath}

Department of Medicine, Agartala Government Medical College Agartala, Tripura, India 